\title{
Temporal Variation of Students' Drug Abuse in Langtang North Local Government Area, Plateau State - Nigeria
}

\author{
Joseph Philip Dangbin
}

\author{
E. S. Samuel \\ Health \& Physical Education Department, University of Nigeria, Nsukka, Enugu state - Nigeria
}

\author{
Doi:10.5901/jesr.2014.v4n7p41
}

\section{Abstract}

This study determined the temporal variation of students' drug abuse in Langtang North Local Government Area - LGA, Plateau state - Nigeria. Descriptive survey research design was employed for the study with data collected from a sample of 752 students', selected through multi stage sampling procedure from all the secondary schools in Langtang North LGA. The instrument for data collection was investigators' structured ten items questionnaire. Face validation of the instrument was obtained through the judgement of five experts. A reliability index of .84 was obtained through the outcome of pilot testing using split half method. Frequencies, percentages and overall means were utilized to answer the research question while Chisquare statistic was used to test the null hypothesis at .05 level of significance. The findings of the study revealed that overall, a slightly higher proportion of the students' in the morning (40.4\%), followed by during dry season (37.6\%), in the evening (33.4\%), during festive period (29.8\%), at weekends (27.8\%), and during rainy season (24.2\%) moderately abused drugs. The study further revealed that students' drug abuse differed according to temporal variation (Cal $\chi_{2}=325.873>\chi_{2}$ tab $=12.59$, $d f=6, p<.05)$. Following from the findings of the study, it was recommended that the Federal Government and NonGovernmental Organizations should endeavour to sponsor people to review the current intervention programs on drug abuse so as to strengthen measures that will further alter the negative attitudes and practices-related to inappropriate use of drugs that still exist. As the review on the current intervention programme is done; the outcome that is consistent with the current drug abuse trends when implemented ought to improve on the current status quo. As the current intervention programme is implemented and adopted, it will further curtail substance abuse thereby having informed and healthy people that will live devoid of drug abuse in Langtang North, Plateau state and the country at large.

Keywords: Temporal variation, students, drug abuse.

\section{Introduction}

For sometimes in man's history, man's inappropriate use of drugs; which lead to disease, has been on the increase. This is because health problems the world over are on the rise among human population. The increase in health problems involve wide spectrum of situations among which is the abuse of drugs by man. The Canadian Drug Misuse Research Division of the Health Research Board-CDMRDHRB (1997/1998) found that the total number of students treated in centres, which made returns to the National Drug Treatment Reporting System - NDTRS rose from 4,910 in 1997 to 6,043 in 1998. Moreover, the board further found that more than seven in ten cases of admission had before the age 20 first used their main drug of abuse while still teenagers (70 per cent) by 1997. Furthermore, the board also noted that while in 1997, 89 per cent of those that reported to NDTRS had first used various drugs were in their teens; by 1998, this figure had increased to 91 per cent, that is, 9 out of 10 . The Plateau state Command of the National Drug Law Enforcement Agency-NDLEA (2009) pointed out that drug abuse victims in Plateau State for years had been on progressive rise since 2005 with 5 victims; 2006 with 33; 2007 with 54; 2008 with 74 victims. By 2009, the number of youths abusing drugs in the state has further risen, with over 500 youths arrested for various drug related offences (Obateru, 2009). Pathetically, the rise in drug abuse as reported NDLEA in Plateau state with some implications on the students in Langtang North occur due to the frequent crises; which youths normally perpetuate mayhem when they were under the influence of drugs, and fall back on drugs to withstand the physiological effect of the mayhem (naij.com September 20, 2012 accessed 25 April, 2014). No wonder, by 2013; Plateau State Command of the NDLEA seized 1,320 kilogrammes of cannabis (Indian hemp) and other prohibited substances with the arrest of 185 suspected drug dealers in the state (nigeriabestforum.com, 2013).Following from the above; substance of abuse, which has led to many health problems has been defined by several authors. 
Drug abuse as conceived by Payne and Hahn (1986) is any chronic, deliberate and excessive use of any drug (that can harm the body). This implies that drug abuse involves any long term or more persistent use of drug that can injure the body. Sizer-Webb, Whitney and Debruyne (1998) refers to drug abuse as the taking of drug for a non-medical purpose and in a manner that can damage a person's health or ability to function. The definition thus implies that drugs prescribed by doctors can be abused if they are taken in a manner that can cause harm to the body system as in the case of overdose. Jonas (2005) conceptualised drug abuse as the use of drug whether over the counter or prescription for purposes other than those prescribed on the product label, which may harm the body. This follows that drug abuse can be detrimental to the abuser's health status, leading to different hazardous conditions in the abuser's health. Such conditions include drug dependence, drug tolerance, drug addiction and drug habituation. Drug abuse as used in this study, refers to any chronic, deliberate and excessive use of any drug, which can damage a person's health or ability to function normally. Although drug abuse can be hazardous, involvement in drug abuse may occur at various times here-in after referred to as temporal variation.

Temporal variation incorporates time (Magnusson, 2000). According to Pridemore Andrew and Spivak (2003), temporal variation relates to variables such as seasons, months, days-of-the week (Fridays, Saturdays), time of day (mornings; afternoons; evenings and night), public holidays (Easter, Christmas, Sallah), National day celebrations (October 1) and national general election days and so on. In this study, temporal variation of drug abuse is interpreted to mean the time or period in which secondary school students' abuse drugs. This could be in the mornings, evenings, at weekends or festive periods, during rainy and dry seasons.

Whereas, drug abuse may occur anytime and anywhere; the occurrence of drug abuse concerning students in many parts of the world including Langtang North LGA, Plateau State-Nigeria where the current study was conducted had been a thing of great concern. The concern was due to lack of documented data especially on students' drug abuse in the area. In as much as there was hardly any official documented data concerning students' drug abuse in Langtang North LGA, Plateau state - Nigeria; the need to determine the temporal variation of students' drug abuse in Langtang North LGA, necessitated the study.

\section{Statement of the Problem}

Students adopt measures that are aimed at helping them to solve their problems in other to improve their health. The students do this as they take drugs based on medical prescription and or supervision, and in a manner that does not constitute potential danger to themselves and others, which according to Sizer-Webb et al (1998), involves the taking of drugs in the right amount, frequency, strength and manner. The consequences of appropriate ingestion of drugs are to preserve, maintain, and promote life, which justify why drugs are taken (Merki, 1990). These measures are necessary because man regards life as very precious irrespective of his place, age, personality and so on.

Unfortunately, drugs are sometimes taken inappropriately by people for many other reasons and occasions. For instance, at cultural and social activities; important events such as birth of a child, marriage, getting a job or promotion, resolution of a conflict, and burial ceremonies are usually celebrated with a generous supply of alcohol giving as food (Dimah \& Gire, 2005). In Plateau state, Obateru (2009) revealed that over 500 youths were arrested for various drug related issues. Even in the recent past, nigeriabestforum.com (2013) indicated that Plateau State Command of the NDLEA seized 1,320 kilogrammes of cannabis (Indian hemp) and other prohibited substances with the arrest of 185 suspected drug dealers in the state. Pathetically, in the area of study, students were often seen loitering around uncompleted buildings; smoking and drinking areas and chemists in the evenings and most parts of the nights. The presence of students' at such places may imply their interest in activities that exist there as they were not owners of such enterprises. Regrettably, no statistical data was available on students' drug involvement in Langtang North LGA. Furthermore, while students may be involved in the use of substances of abuse that existed in the state; this study determined the rate of students' involvement in drug abuse in Langtang North LGA.

Additionally, although Dimah and Gire (2005) conducted a study on alcohol use in Benue state; it involved 183 participants both young and matured adults within 18-72 years and of different occupations, with Chi square and percentages. The present study determined drug abuse among 752 respondents of 11-18 years age group, different location and of subjects in the study; time involved in drug abuse and in addition means, Chi square and percentages were used for the study. The differences were the gaps this study filled.

Moreover, while the study of Dimah and Gire (2005) was conducted on drug use; the findings implicated age. Therefore, it was clear that the implication was worrisome especially concerning the actual status of students' temporal variation of drug use in Langtang North LGA. From the foregoing, it appeared that the above situation may not be 
different from what is happening among students in Langtang North LGA, Plateau State-Nigeria. The pertinent question therefore was: what is the temporal variation of students' drug abuse in Langtang North LGA, Plateau state-Nigeria? The study sought to answer this research question. To further guide this study, a null hypothesis of no statistically significant difference in students' drug abuse according to temporal variation was postulated and tested at .05 level of significance.

\section{Significance of the Study}

The present study was designed to determine the temporal variation of students' drug abuse in Lanagtang North LGA, Plateau state - Nigeria. Data generated would be beneficial to Health Educators-HE, School Authority-SA, Researchers, Social Welfare Units (SWU) and NDLEA.

$\mathrm{HE}$ would use the findings on temporal variation of students' drug abuse to add to the wealth of knowledge they have concerning students' drug issues in schools, which would help them to determine the premium that ought to be associated with drugs topics to be taught. SA on the other hand would use the findings to establish how to sensitize its teachers on the need to be vigilant on students. Moreover, the findings would serve as a baseline data that would help as a resource for reference. In addition, the gap created by this study would be filled by other researchers' future studies.

SWU would use the findings on temporal variation to establish the actual period that students would be involved in abusing drugs and plan on how best to tackle such problem towards the betterment of the society in Langtang North, Plateau state and the country at large. The NDLEA, on the other hand, would use the findings to establish when and how to step up strategies concerning drug abuse on students by establishing the period that require more attention on drug enlightenment to students. This can be realised through the presentation of talks, seminars and symposia by NDLEA officials and the provision and distribution of posters and hand bills, which ought to contain the negative consequences of drug involvement by students.

\section{Methods}

In order to achieve the purpose of the study, the descriptive survey research design was employed. Multi stage sampling technique was used to draw seven hundred and fifty two (representing two per cent of 37600 adolescents' population) students from all the secondary schools in Langtang North LGA. The instrument for data collection was a ten item drug abuse questionnaire (DAQ), which required the students to respond yes or no options. The copies of the questionnaire were distributed and collected back on the spot through the assistance of five trained researcher assistants.

Face validation of the instrument was obtained through the judgment of five experts drawn from Health and Physical Education, Psychology and Measurement and Evaluation Departments, all from the University of Nigeria, Nsukka. The reliability of the instrument was determined through the outcome of the pilot testing using split half method, and reliability index of .84 was obtained. The data generated for the study were analyzed using frequencies, percentages and means to answer the research question while chi-square statistic was employed to test the only null hypothesis at .05 level of significance.

Overall mean was applied in determining students drug abuse status based on the researchers' developed scale. In this regard, a score less than nine per cent was considered not abuse level of drug abuse; $10-29$ per cent was considered lowly abused level of drug abuse; $30-49$ per cent, moderate abuse level of drug abuse; $50-79$ per cent highly abused level of drug abuse, and 80 per cent and above very highly abused level of drug abuse.

\section{Results}

In presenting the results of the study, the research question was answered first using percentages and overall means. This was followed by summaries of chi-square statistic used in testing the hypothesis at .05 level of significance.

\subsection{Research question one}

What is the temporal variation of students' drug abuse? Data answering this research question are indicated in Table 1. 
Table 1: Temporal Variation of Students' Drug Abuse

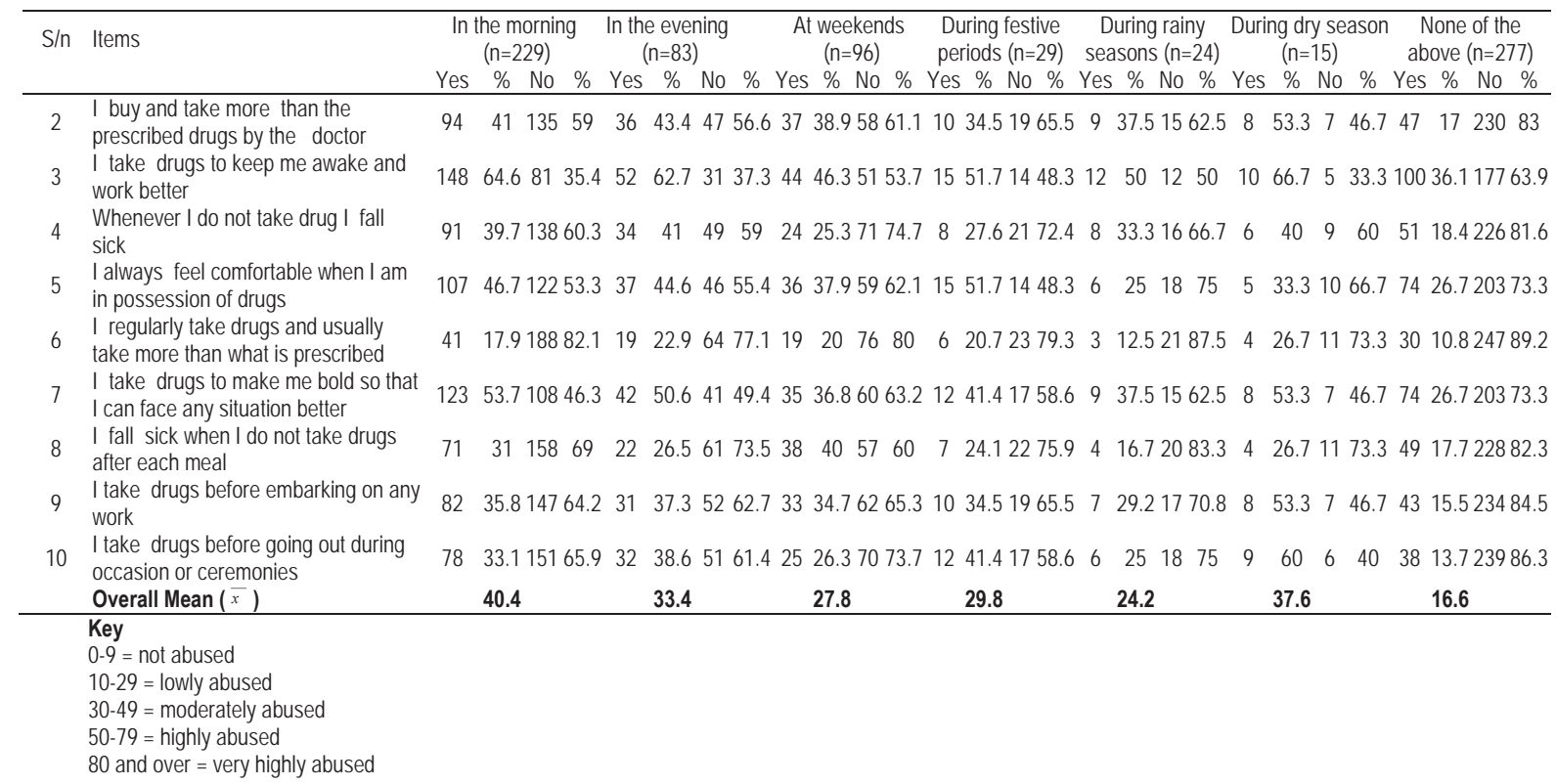

Source: Field survey by Investigators, 2014

Data in Table 1 show that overall, a slightly higher proportion of the students' in the morning (40.4\%) followed by during dry season (37.6\%), in the evening (33.4\%), during festive period (29.8\%), at weekends (27.8\%), and during rainy season (24.2\%) moderately abused drugs. The Table further show that slightly higher proportions of the students' highly abused drugs in such items as in taking drugs to keep awake and work better during dry season (66.7\%), followed by in the morning (64.6\%) than in the evening (62.7\%), during festive period $(51.7 \%)$, during rainy season (50.0\%), and at weekends (46.3\%); and students who took drugs before going out during occasions or ceremonies during dry season were $(60.0 \%)$ followed by during festive period (41.4\%) than in the evening (38.6\%) in the morning (34.1\%), at weekend (36.3\%) and during rainy season (25.0\%).

Additionally, Table 1 further shows that slightly higher proportions of the students highly abused drugs in such items as taking drugs to make them bold to be able to face any situation better in the morning (53.7\%), during festive season (53.3\%) and in the evening (50.6\%) than those during festive period (41.4\%), rainy season (37.5\%) and at weekends (36.8\%); buying and taking more than the prescribed drugs by their doctor when they were sick during dry season were (53.3\%) followed by in the evening (43.4\%) than in the morning (41.0\%), at weekends (38.9\%), during rainy season (37.5\%) and festive period (34.5\%); and students who took drugs before embarking on any work during the dry season were (53.3\%), in the evening (37.3\%) and in the morning (35.8\%) than those during festive period (34.5\%), at weekend (34.7\%) and during dry season (29.2\%). Whereas, only a slightly higher proportion of the students' highly abused drugs by always feeling comfortable when they were in possession of drugs during festive period (51.7\%) followed by in the morning (46.7\%) than at weekends (37.9\%), during dry season (33.3\%) and during rainy season (25.0\%).

The Table also reveals that slightly higher proportions of the students' moderately abused drugs in items such as: students' falling sick whenever they did not take drugs in the evening (41\%) followed by during dry season (40\%) in rainy season, (33.3\%) during festive period, (27.6\%), and at weekends (25.3\%); and students who felt sick when they did not take drugs after each meal at weekends $(40.0 \%)$ followed by in the morning $(31.0 \%)$ than during dry season $(26.7 \%)$ in evening (26.5\%), during festive period (24.1\%) and rainy season (16.7\%). Only a slightly higher proportion of the students lowly abused drugs by regularly taking and usually more of it than it was prescribed to them by their doctor during dry season (26.7\%), followed by in the evening (22.9\%) than during festive period (20.7\%), at weekends (20.2\%), in the morning (17.9\%) and during rainy season (12.5\%). 


\section{Hypothesis 1}

There is no statistically significant difference in students' drug abuse according to temporal variation. Data verifying this hypothesis are contained in Table 2.

Table 2: Result of Chi-Square Values Testing the Null Hypothesis of No Significant Difference in Students' Drug Abuse According Temporal Variation

\begin{tabular}{|c|c|c|c|}
\hline Items of Drug Abuse & yes no yes no yes no yes no yes no yes no yes no & $\begin{array}{c}\text { Cal } \\
\chi^{2} \\
\text { value }\end{array}$ & $\begin{array}{l}\text { Table } \\
\chi_{2} \text { df } \\
\text { value }\end{array}$ \\
\hline \multicolumn{4}{|l|}{ S/n Gender } \\
\hline 2. I buy and take more than the prescribed drugs by the doctor & $94 \quad 1353647375810199915 \quad 8 \quad 7 \quad 47 \quad 230$ & $47.937^{\star}$ & 12.596 \\
\hline 3. I take drugs to keep me awake and work better & 1488152314451151412121055100177 & $48.413^{*}$ & 12.596 \\
\hline 4. Whenever I do not take drug I fall sick & $9113834 \quad 492471 \quad 8 \quad 21 \quad 8 \quad 16 \quad 6 \quad 9951 \quad 226$ & $34.983^{\star}$ & 12.596 \\
\hline 5. I always feel comfortable when I am in possession of drugs & 10712237463659151461851074203 & $28.115^{\star}$ & 12.596 \\
\hline 6. I regularly take drugs and usually take more than what is prescribed & 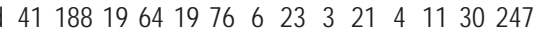 & $11.99 * \star$ & 12.596 \\
\hline 7. I take drugs to make one bold so that I can face any situation bette & r $123106424135601217901587_{14} 74203$ & $43.657^{\star}$ & 12.596 \\
\hline 8. I fall sick when I do not take drugs after each meal & $71 \quad 15822613857 \quad 7 \quad 22 \quad 4 \quad 20 \quad 4 \quad 1149228$ & $23.794^{*}$ & 12.596 \\
\hline 9. I take drugs before embarking on any work & $821473152336210197617 \quad 8 \quad 7 \quad 43 \quad 234$ & $38.983^{\star}$ & 12.596 \\
\hline 10. I take drugs before going out during occasion or ceremonies & $78151325125701217 \quad 6 \quad 1896 \quad 6 \quad 38239$ & $48.001^{*}$ & 12.596 \\
\hline Cluster value & & $325.873^{*}$ & 12.596 \\
\hline
\end{tabular}

Results in Table 2 reveal a cluster calculated $\chi^{2}$ value of 325.873 with six degrees of freedom which is greater than the table $\chi^{2}$ value of 12.59 at .05 level of significance. The null hypothesis of no statistically significant difference in students' drug abuse according to temporal variation was therefore rejected. This means that students' drug abuse differed according to temporal variation.

The table further indicates calculated $\chi^{2}$ values for "taking drugs to keep awake and work better" $\left(\chi^{2}=48.413>\right.$ 12.59); "taking drugs before going out during occasions" ( $\left.\chi^{2}=48.001>12.59\right)$; "buying and taking more than the prescribed drugs" ( $\left.\chi^{2}=47.937>12.59\right)$; "taking drugs to feel bold and face any situation" ( $\left.\chi^{2}=43.657>12.59\right)$; "taking drugs before embarking on any work" ( $\left.\chi_{2}=38.983>12.59\right)$; "falling sick when drugs is not taken" $(\chi 2=34.983>$ 12.59); "feeling comfortable when in possession of drugs" ( $\chi 2=28.115>12.59)$; and "falling sick after each meal without drugs" ( $\left.\chi^{2}=23.794>12.59\right)$ were greater than the table $\chi^{2}$ value of 12.59 with six degrees of freedom, and .05 level of significance. The null hypothesis was, therefore, rejected for these items. This implies that students' drug abuse differed according to whether it was in the morning, evening, at weekend, during festive periods, rainy season and dry seasons that students' abused drugs. The table also reveals that a calculated $\chi 2$ for "taking drugs more than was prescribed" ( $\chi 2$ $=11.990<12.59$ ) was less than the table $\chi^{2}$ value of 12.59 with six degrees of freedom at .05 level of significance. The null hypothesis was accepted for this item. This implies that students' abuse drugs in the morning, evening, at weekend, during festive periods, rainy and dry seasons.

\section{Discussion}

The finding in Table 1 of slightly higher proportion of students' who moderately abused drugs in the morning (40.4\%) followed by during dry season than in the evening, during festive period than at weekends, and during rainy season was not expected and therefore surprising because early hours of the day are mostly periods that students usually prepare to begin the days' pursuit, which is expected to begin in a manner that one will be with his complete senses to be able to get the best for the day. However, students who engage in the taking of drugs during the early part of the day; may not benefit much from the normal day's activities since they may be under the influence of such drug. For instance, such students who abused drugs may not have the time to participate in all the school routine of the normal school programme, which involves morning prayers, attending assembly, lessons and so on regularly, because they may be under the influence of drugs at these times. This finding agrees with the findings of Gwaza (1980), Pozotto (1990) and Keller (1991) who observed that periods such as those of the Christmas and Sallah, bazaar, harvest as well as public holidays are the periods, which students' abuse drugs. This finding implies that when students get involved in drug abuse in the mornings while in school, such students' are likely to be involved in absenteeism, bullying others, poor 
performance in school work.

Table 1 further shows that there was high proportion of students' who take drugs to make them feel bold to face any situation better during dry season. The findings was surprising and therefore not expected because ordinarily where students depend on drugs to face their work in school, the danger lies that such student will end up being unable to do anything meaningful unless they ingest drugs. This attitude can affect students' health to a large extent, leaving them dependent on drugs. The implication of this finding may be that students may have been influenced to abusing drugs due to the sensationalizing influence of uncontrollable advertisements over the media depicting drugs as beneficial.

The Results in Table 2 reveal that there was no statistically significant difference in students' drug abuse according to temporal variation. This finding was expected and therefore not surprising because of the availability and accessibility of the substances of abuse that can easily be affordable by the students with ease; and without adequate restrictions enforced on students' to forestall such anomaly. In addition, the weak restrictions mechanism apparatus in the control of drug abuse may be responsible to this situation. Furthermore, since substances of abuse were always affordable, available and accessible and were without adequate or strict restrictions and control mechanisms in place to forestall such anomaly; students were left at the mercy of fate in the abuse of drugs. On the bases of the above, students abused drugs anytime they so desire.

\section{Conclusion}

Based on the findings of the study, the following conclusions were drawn:

1. A slightly higher proportion of students' moderately abused drugs in the morning (40.4\%) followed by during dry season than in the evening, during festive period than at weekend, and during rainy season respectively.

2. Students' drug abuse differed according to temporal variation of in the mornings, evenings and at weekends as well as during festive periods, rainy seasons and dry seasons. .

\section{Recommendations}

In line with the findings above, the following recommendations were made:

1. That people should continually be sensitized on the effects of drug abuse. This can be achieved through organizing workshops, seminars and conferences at community level. These fora of sensitization will promote knowledge that can be used in changing the negative attitude of humans' towards drug abuse thus leaving them healthy.

2. Following from the findings of the study, it was recommended that the Federal Government and NonGovernmental Organizations should endeavour to sponsor people to review the current intervention programs on drug abuse so as to strengthen measures that will further alter the negative attitudes and practices-related to inappropriate use of drugs that still exist. As the review on the current intervention programme is done; the outcome that is consistent with the current drug abuse trends when implemented ought to improve on the current status quo. As the current intervention programme is implemented and adopted, it will further curtail substance abuse thereby having informed and healthy people that will leave devoid of drug abuse in Langtang North, Plateau state and the country at large.

3. Since drug abuse occurs at all time among students who may in future constitute the engine room of leadership in Langtang North in particular and Plateau state at large, there is the need to strengthen by recruiting and giving adequate training from time to time to the NDLEA and relevant agencies to curb this ugly trend. As this is done, the NDLEA and relevant agencies will be strengthened to move to the nooks and crannies of the area and hunt to forestall this situation; and as a result, curb this monster.

4. The school authorities should endeavour to step up their efforts in curbing drug abuse in their various schools. This can be done by ensuring that teachers on duty do their assignments appropriately. Moreover, they should be in turn supervised by their head teachers from time to time so as to ensure that the right thing is done at the right time, in the right frequency and manner.

\section{References}

Canadian Drug Misuse Research Division of the Health Research Board-CDMRDHRB (1997/98).Definitions used in the bulleting. Irish: Monitoring Centre for Drugs and Drug Addiction REITOX Network.

Dimah, A., \& Gire, J. A. (2005). The health and economic consequences of alcohol use in Central Nigeria.African Journal of Drug and 
Alcohol Studies, 4 (1\&2) 44-53.

Gwaza, P. A. (1980). The historical perspectives of alcohol and tobacco use. Makurdi: Satos Printing Press.

Jonas, M. (2005).Mosby's dictionary of complementary and alternative medicine.Elsevier.

Keller, C. B. (1991). Health science for tropical schools. London: Wilfred Publishing Company.

Magnusson, M. S. (2000). Discovering hidden time patterns in behavior: T-patterns and their detection. Behavior Research Methods, Instruments \& Computers, $32,93-110$.

Merki, M. B. (1990). Discussion for teen health. Illinois. Glencoe/Macmillan/ McGraw-Hill.

Naij.Com (2012, 20th September). Drug abuse high in Jos, difficult to fight, NDLEA (20 September, 2012).Retrieved @http://news.naij.com/9282.html accessed 25 April, 2014.

National Drug Law Enforcement Agency-NDLEA (2009).Plateau state Command, Jos, Plateau state - Nigeria.

Nigeria Best Forum.Com (2013, 21st August). NDLEA Arrests 185 suspected drug dealers in Plateau. Retrieved @ http://www.nigerianbestforum.com/index.php?topic=307004.0 accessed 25 April, 2014.

Obateru, T. (2009, June).Drug addiction worries Plateau. Vanguard newspapers.Retrieved @http://www.vanguardngr.com/2009/06/drug-addiction-worries-plateau/ Accessed 25 April, 2014.

Payne, W. A., \& Hahn, D. B. (1986). Understanding your health. St. Louis: Times Mirrow College Publishing.

Pozotto, R. (1990). Alcohol and nutrition.Clinical Journal, 19 (2), 68-74.

Pridemore, W. A., Andrew, I., \& Spivak, M. A. (2003).Patterns of suicide mortality in Russia.Suicide and Life-Threatening Behaviour, 23, 132-150.

Sizer-Webb, F., Whitney, E. N., \& Debruyne, L. N. (1998).Health: making choices. New-York: West Publishing Company. 